\title{
Probabilistic patterns of inundation and biogeomorphic changes due to sea-level rise along the northeastern U.S. Atlantic coast
}

\author{
Erika E. Lentz $\mathbb{D} \cdot$ Sara L. Zeigler $\cdot$ E. Robert Thieler $\cdot$ Nathaniel G. Plant
}

Received: 20 February 2020/ Accepted: 29 September 2020/Published online: 7 November 2020

(C) The Author(s) 2020

\begin{abstract}
Context Coastal landscapes evolve in response to sea-level rise (SLR) through a variety of geologic processes and ecological feedbacks. When the SLR rate surpasses the rate at which these processes build elevation and drive lateral migration, inundation is likely.

Objectives To examine the role of land cover diversity and composition in landscape response to SLR across the northeastern United States.

Methods Using an existing probabilistic framework, we quantify the probability of inundation, a measure
\end{abstract}

Electronic supplementary material The online version of this article (https://doi.org/10.1007/s10980-020-01136-z) contains supplementary material, which is available to authorized users.

E. E. Lentz $(\bowtie) \cdot$ E. R. Thieler

U.S. Geological Survey, Woods Hole Coastal and Marine

Science Center, Woods Hole Rd, Woods Hole,

MA 02540, USA

e-mail: elentz@usgs.gov

E. R. Thieler

e-mail: rthieler@usgs.gov

S. L. Zeigler · N. G. Plant

U.S. Geological Survey, St. Petersburg Coastal and

Marine Science Center, St. Petersburg,

FL, USA

e-mail: szeigler@usgs.gov

N. G. Plant

e-mail: nplant@usgs.gov of vulnerability, under different SLR scenarios on the coastal landscape. Resistant areas-wherein a dynamic response is anticipated-are defined as unlikely $(\mathrm{p}<0.33)$ to inundate. Results are assessed regionally for different land cover types and at 26 sites representing varying levels of land cover diversity.

Results Modeling results suggest that by the 2050s, $44 \%$ of low-lying, habitable land in the region is unlikely to inundate, further declining to $36 \%$ by the 2080s. In addition to a decrease in SLR resistance with time, these results show an increasing uncertainty that the coastal landscape will continue to evolve in response to SLR as it has in the past. We also find that resistance to SLR is correlated with land cover composition, wherein sites containing land cover types adaptable to SLR impacts show greater potential to undergo biogeomorphic state shifts rather than inundating with time.

Conclusions Our findings support other studies that have highlighted the importance of ecological composition and diversity in stabilizing the physical landscape and suggest that flexible planning strategies, such as adaptive management, are particularly well suited for SLR preparation in diverse coastal settings.

Keywords Sea-level rise - Land cover .

Biogeomorphology · Inundation · Dynamic response · Coastal landscape $\cdot$ Probability $\cdot$ Likelihood 


\section{Introduction}

Coastal landscapes are dynamic systems. Their landforms - such as barrier-island and mainland beaches, headlands and cliffs, and estuaries and wetland systems-respond to wind (e.g. Houser et al. 2015), waves (e.g. Roelvink et al. 2009; Leonardi and Fagherazzi 2014), water levels (e.g., Sallenger 2000), currents (Sherwood et al. 2014), sediment supply (Brooks et al. 2017), vegetation (Gedan et al. 2011), and underlying geology (e.g., Harris et al. 2005). As a result, multiple biogeomorphic states exist both at landscape scales and within ecological regions on the landforms themselves (Stallins 2005). A spectrum of timescale-dependent disturbance categories (Donohue et al. 2016) — from pulse (i.e., shortlived, sharp perturbations, particularly storms) to press (i.e., constant, long-term change, such as sea-level rise [SLR])-drive dynamism and state changes across coastal landscapes (Lorenzo-Trueba and Ashton 2014). Furthermore, pulse drivers will be amplified by press drivers, particularly SLR (Arns et al. 2015). Consequently, understanding the SLR response can be used to inform proactive planning strategies by providing information as to where and at what point changes in biogeomorphic states are more likely to occur (Pelletier et al. 2015) so that hazard mitigation options can be explored.

Landscape-scale assessment and prediction requires consideration of both the ecology and geomorphology of the coast, as well as acknowledgement of uncertainty around disturbance categories and the consequent landscape change that may result. The concept of dynamic equilibrium posits that there are a range of geomorphic landform states that fluctuate around a central tendency or equilibrium state (Ahnert 1994), such as in coastal settings where dynamic change is frequent and can be dramatic (Cooper et al. 2007). Although a system may never reach true equilibrium (e.g., Lorenzo-Trueba and Ashton 2014), understanding the range of forms it may take can better inform predictions of behavior and change. Similarly, alternative stable state theory suggests that an environment or ecosystem consists of a specific set of biotic and abiotic conditions in a 'state' that is stable under relevant timescales. A series of possible alternative stable states may exist for that environment (McGlathery et al. 2013); however, in this theory, transitions between states occur through major perturbations that shift ecologic equilibria (Holling 1973). When viewed in light of evaluating landscape change, alternative stable states might be viewed as significant shifts of the biogeomorphic equilibrium state itself, such that a return to the previous equilibrium state is unlikely due to system instability (Beisner et al. 2003; Scheffer et al. 2012). The state shift itself may also vary, with some shifts occurring both abruptly and rapidly via a tipping point, whereas others may occur more gradually as a critical threshold is surpassed (Scheffer et al. 2012) (Fig. 1). Along the coast, where natural resource needs, ecosystem services, and human interests often vie for different uses of limited land area, accounting for where and when changes in state may be more and less likely across the landscape can inform planning and management decisions.

The amplification of coastal change drivers under future climate scenarios has the potential to enhance instabilities such that biogeomorphic changes that can result in a state shift in coastal systems are accelerated (Schneider 2004; Moore et al. 2010; Scheffer et al.

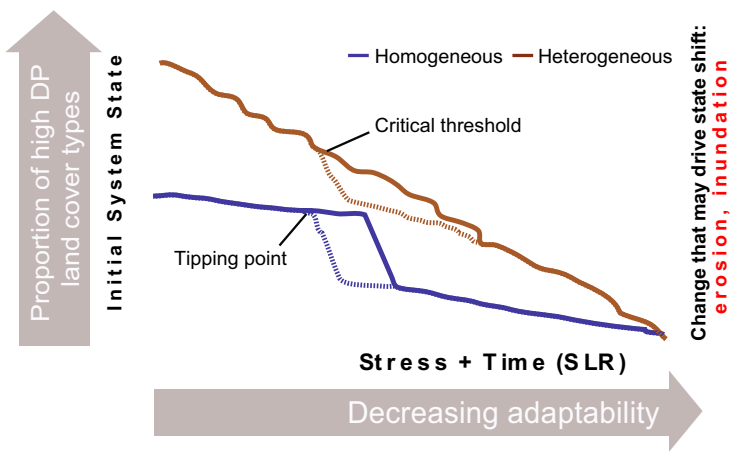

Fig. 1 Conceptual schematic plot illustrating the hypothesized relationship between land cover composition and diversity and response to sea-level rise (SLR) through time ( modified from Scheffer et al. 2012). Here, we predict that heterogenous sites, which are more likely to contain a high proportion of land cover types with a high probability of responding dynamically to SLR (high DP; e.g., undeveloped barrier islands), will exhibit steady declines in dynamic land cover states and overall adaptability to inundation that will be difficult to reverse once a critical threshold (which may be difficult to detect) is reached (brown line). Alternatively, we predict that homogenous sites, which are more likely to have a lower proportion of high DP land cover types (e.g., developed cities), will exhibit a clear tipping point (blue line). When this tipping point is reached, the site will exhibit an abrupt loss of adaptability and become more vulnerable to inundation. Dashed lines show how an additional pulse disturbance (e.g., storms) may have the potential to accelerate these trends 
2012; Wang and Temmerman 2013; Brantley et al. 2014; Eslami-Andergoli et al. 2015; Kirwan et al. 2016; Philips 2018; Phillips 2018). Global sea level rise projections predict increases between 0.3 and $1.2 \mathrm{~m}$ by 2100 (Church et al. 2013; Kopp et al. 2014; 2019). Projections along the North American northeastern and mid-Atlantic coasts are variable (Kopp 2013; Sweet and Park 2014; Goddard et al. 2015), with sea levels projected to be higher than the global average (Sweet et al. 2017). Tidal flooding events have increased dramatically at many locations since the 1950s throughout the Northeast (Sweet and Park 2014) and are projected to increase to 'every other day' events or more often in the region by 2100 (Sweet et al. 2018). Furthermore, predictions of future storm activity show more intense and frequent events are anticipated in the coming decades in regions like the North American Atlantic coast (Knutson et al. 2010; Neumann et al. 2015b). Biogeomorphic change associated with SLR and changes to the storm regime can manifest in a variety of state shifts across the landscape, from increased vulnerability to lateral migration, chronic erosion, disaggregation, and inundation, as exemplified in coastal barrier systems and marshes throughout the Northeast (FitzGerald et al. 2008; Vinent and Moore 2015). These outcomes, and inundation in particular, can lead to major social, economic, and ecological consequences, such as mass migration, cascading infrastructure impacts, and habitat loss (Leatherman 2001; Hinkel et al. 2014; Hauer et al. 2016), making consideration of most-likely and worst case scenarios important to inform adaptation planning (Hauer et al. 2016; Hino et al. 2017).

Widely available inundation models (e.g., Marcy et al. 2011; Strauss et al. 2012) depict broad-scale flooding and submergence but do not consider the biogeomorphic complexity, natural variability, and dynamism of coastal systems (FitzGerald et al. 2008; Plant et al. 2016). Because of these omissions, inundation models tend to geospatially overestimate or sometimes underestimate coastal inundation, failing to capture where ecosystems or habitat important from a land and species management perspective may be preserved or adaptively managed (e.g. Kirwan et al. 2016). In response to this information gap, Lentz et al. (2015a; 2016) developed a probabilistic modeling approach (Fig. 2) for the northeastern United States to account for the role of land cover variability and dynamism in the response to SLR. The model predicts the likelihood that a given coastal area will exhibit a dynamic response, in which that area either maintains its current state (e.g., a beach remains a beach) or could transition to another non-submerged state (e.g., a forest becomes a marsh). In the Lentz et al. (2015a; 2016) model, inundation is the opposite of a landscape-elevation-sustaining dynamic response.

Here, we apply the outcomes of Lentz et al. (2015a, b, 2016) to provide a first order assessment of how land cover type and composition affect the potential for biogeomorphic changes across the northeastern U.S. Atlantic coast that may lead to a state shift (Fig. 3). We first used likelihood ranges (Mastrandrea et al. 2010) to define an area's probability of being inundated at different time scales (2020s through 2080s) and explored temporal shifts in likelihood categories regionally, by land cover type, and by site to explore where and when biogeomorphic changes were likely to occur. Using this approach allowed us to also evaluate the applicability of likelihood ranges (based on the International Panel on Climate Change's [IPCC's] conventions) to discretize our probabilistic outcomes and provide meaningful first-order information on landscape change in response to SLR. Selected sites (Fig. 3) included cities (e.g., Boston, MA; New York, NY) as well as federally protected national wildlife refuges (NWR; e.g., Monomoy NWR, Chincoteague NWR) and national seashores (NS; e.g., Cape Cod NS, Fire Island NS). Percentages of land cover types within sites were calculated to gauge the relative influence of land cover composition and diversity on inundation potential, wherein we sought to identify sites both vulnerable to inundation as well as those with land cover compositions more resistant to SLR increases. Methodologies and the presentation of results and their inherent uncertainties were carefully selected to facilitate use by management communities and the broader public.

We hypothesized that inundation resistance would vary among sites based on their land cover compositions, that this resistance would vary among sites and with time (i.e., SLR increases), and that settings dominated by dynamic land cover types would have a higher and more gradual resistance to inundation with time than developed settings. More specifically, and as illustrated in Fig. 1, we expected that the composition and/or diversity of a given site would influence the rate of biogeomorphic change that could ultimately lead to a state shift. We predicted that heterogeneous sites 
composed of more dynamic land cover types would exhibit steady declines in SLR resistance reflective of critical thresholds being surpassed, such as high dunes that transition to low dunes to washover to inundation. In contrast, we predicted that more homogenous sites with less adaptable land cover types would exhibit abrupt change as a tipping point is reached, such as the inundation of a developed waterfront. Through this approach, we demonstrate how our coastal response outcomes can be applied to inform management targets at a variety of spatial and temporal scales by indicating: (1) inundation resistance; 2) the potential for substantial biogeomorphic change that may result in a state shift, and 3) the temporal susceptibility of an area to such a change.

\section{Materials and methods}

Previous work: coastal response to sea-level rise model

Lentz et al. (2015a, b, 2016) predicted and mapped the probability of inundation vs. dynamic coastal response
Fig. 3 Location map showing the regional (light gray) and sitespecific (green, orange, and purple) extents for predictions of coastal response to sea-level rise. Sites, labeled here, included federally protected national wildlife refuges (NWRs) and national seashores (NSs) as well as cities. Red boxes denote site locations highlighted in Fig. 7

to future SLR in the northeastern U.S. using a probabilistic framework (i.e. a Bayesian network, or $\mathrm{BN})$. Dynamic probability was defined as the likelihood that a land cover type at a given location will either avoid inundation and maintain its existing state (e.g. a marsh vertically accreting to keep pace with SLR) or transition to another non-submerged state. Examples of a transition include a forest transitioning to a marsh or a marsh transitioning to a different marsh type or even sand ridge, as in Phillips (2018 a, b), the latter accounting for potential landward migration. Results are viewed as an inverse relationship, wherein an area that has a low dynamic probability has a high inundation probability. In other words, the inundation probability can be calculated by simply subtracting the dynamic probability from 1 . Total uncertainty in the predicted outcomes, where inundation or dynamic

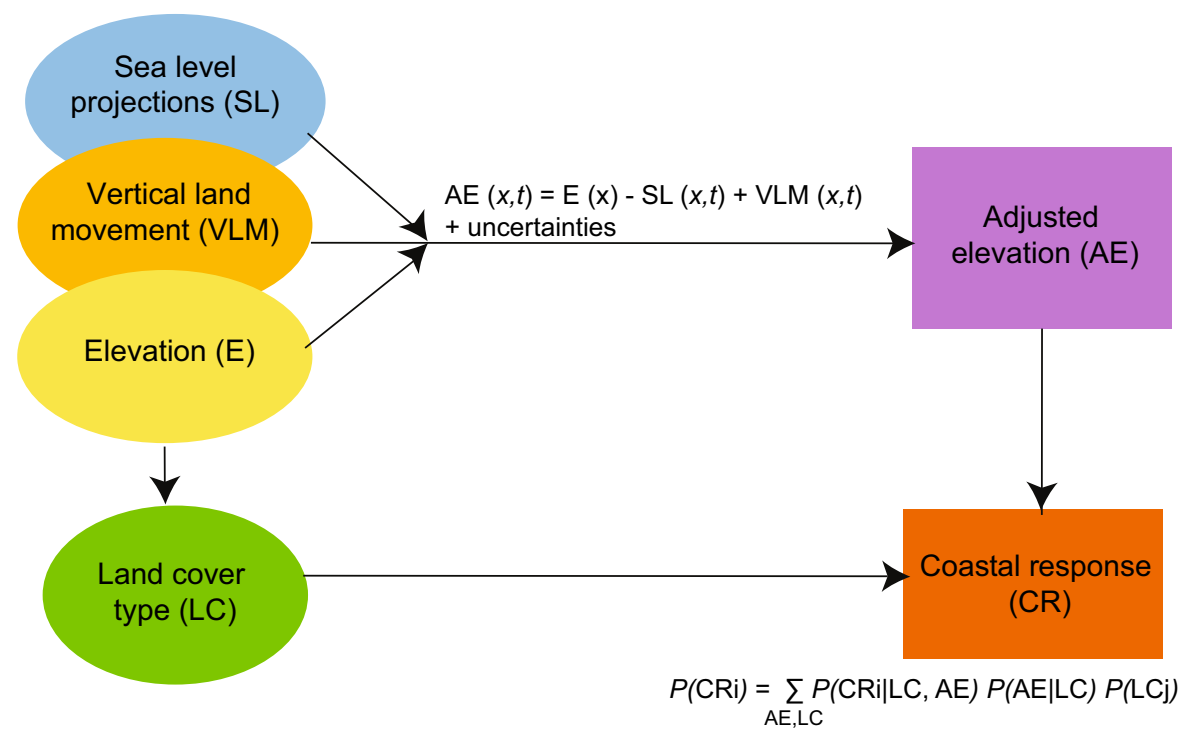

Fig. 2 Diagram of the coastal response (CR) model, which predicts the likelihood that a given location will be inundated under various sea-level rise (SLR) scenarios (Lentz et al. 2015a, 2016). The model is a Bayesian network, with data inputs listed on the left (ovals) and predicted outcomes on the right (rectangles). For the coastal response output, a location could exhibit either a dynamic response to SLR-meaning that it could remain in its current state (e.g., beach remains a beach) or transition to another, above-water state (e.g., marsh becomes a forest)—or, alternatively, be inundated under rising sea levels. Correlations among variables are represented by arrows. Equations show deterministic and probabilistic equations used to generate conditional probabilities. Here, $x$ and $t$ indicate spatial and temporal dependence, respectively, and $i$ and $j$ joint correlations of occurrence $i$, at a specific location, $j$ 


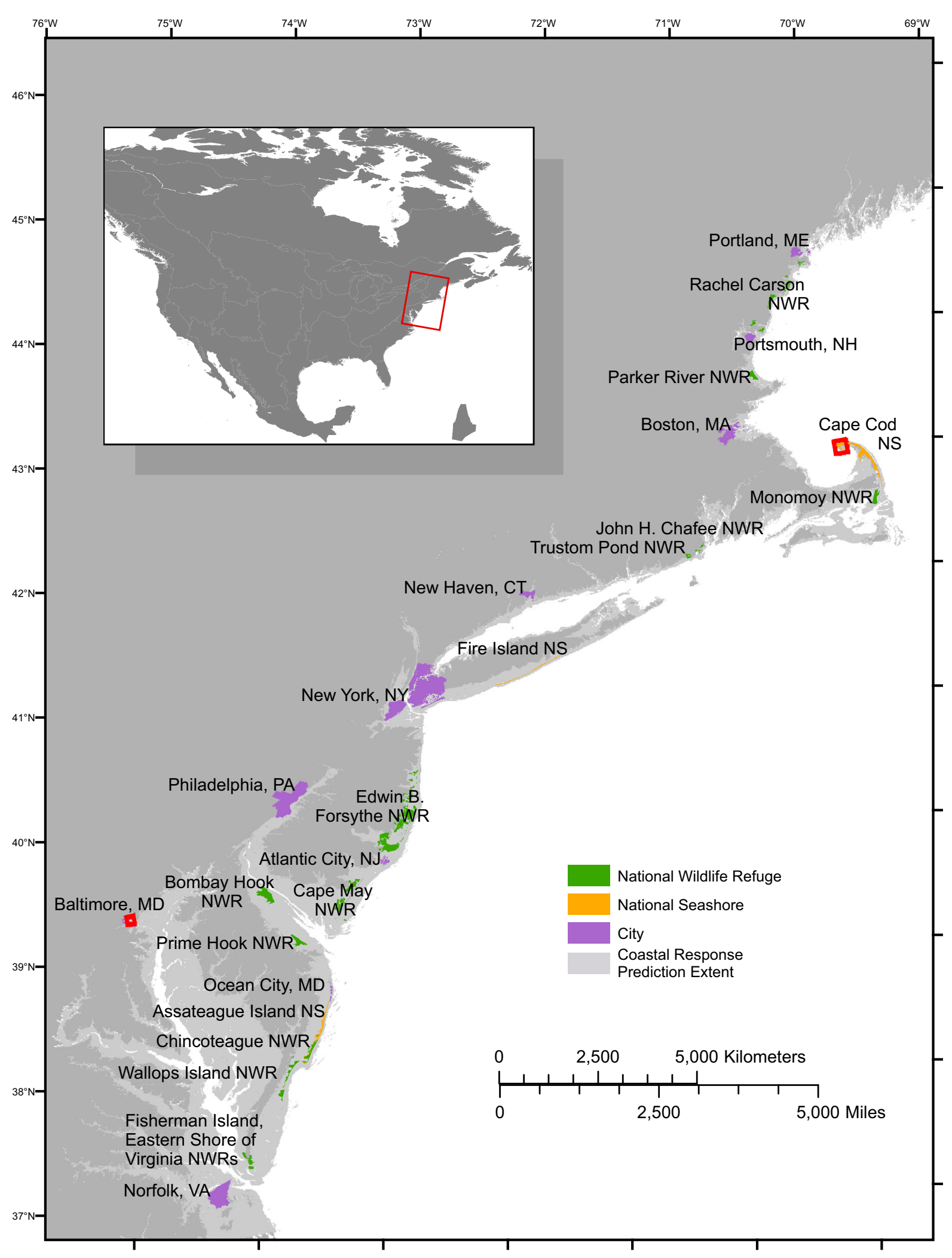


response were equally likely, has a value of 0.5 in the model.

Predictions were generated for a $38,000 \mathrm{~km}^{2}$ coastal area from Maine to Virginia at $30 \mathrm{~m}$ by $30-\mathrm{m}$ resolution in four decadal-scale time steps: the 2020s, 2030s, 2050s, and 2080s. The study area was bounded by the $10-\mathrm{m}$ elevation contour inland to $10 \mathrm{~m}$ offshore elevation contour. To generate predictions of dynamic response, the $\mathrm{BN}$ (Fig. 2) was structured to first predict the adjusted land elevation (AE) with respect to relative SLR for a given decade. Dynamic response (or inundation) likelihoods were estimated by coupling predicted AE ranges with the likelihood of generalized land cover types to dynamically adapt vs. inundate, further described at the end of this section.

SLR, vertical land movement, elevation, and land cover datasets were the inputs used to build and train the BN (Fig. 2). Relative sea-level rise (RSLR; vertical land movement and SLR) served as the driver to project future inundation (based on current elevation), and land cover data were used to evaluate potential future morphologic and/or ecologic dynamic response based on studies and expert knowledge on how they adapt to SLR (as an alternative to inundation). SLR values were comprised of three components using the 2014 IPCC's representative concentration pathways (RCPs) 4.5 and 8.5: ocean dynamics (generated from 24 Coupled Model Intercomparison Project phase 5 (CMIP5) models; Taylor et al. (2012); ice melt (using Antarctic ice sheet estimates from Bamber and Aspinall 2013, and glacier and ice caps based on Marzion et al. 2012 and Radić et al. 2013); and global land water storage (as in on Church et al. 2013). Aggregated percentile ranges from these three components based on RCPs 4.5 and 8.5 were used to provide a SLR scenario and corresponding uncertainty via an elevation range for each decade used in our model. The projected scenario ranges by decade are as follows: $2020 \mathrm{~s}, 0$ to $0.25 \mathrm{~m}$; 2030s, 0.25 to $0.5 \mathrm{~m} ; 2050 \mathrm{~s}, 0.5$ to $0.75 \mathrm{~m}$; and 2080s, 0.75 to $2 \mathrm{~m}$. These ranges generally align well with the most likely or highest probability scenarios used in the 2018 National Climate Assessment and as reported in Sweet et al. (2017), albeit without vertical land movement effects. Instead, local vertical land movement rates driven by glacial subsidence were incorporated using long term GPS CORS station data (Sella et al. 2007) as well as long term tide gauge information
(Zervas et al. 2013) in a separate node (Fig. 2). For simplicity, these data were kept as time independent in the $\mathrm{BN}$, meaning that, for a given decade, the most likely RSLR scenario range was selected and applied. Elevation values were obtained from the highestresolution land-elevation values-National Elevation Dataset at $1 / 9$ and $1 / 3$ arc-second resolutions, with \pm 0.42 and $1.25 \mathrm{~m}$ error respectively (Gesch 2007), and Coastal Relief Model with $\pm 1.0 \mathrm{~m}$ error (National Oceanic and Atmospheric Administration 2014) —and converted from the North American Vertical Datum to mean high water using VDatum conversion grids (National Ocean Service, 2013).

Land cover data were incorporated using five broad land cover categories that are anticipated to respond to SLR in an ecologically or morphologically distinct manner from one another (Table 1). Land cover categories were generalized from the land cover dataset created by the Designing Sustainable Landscapes project (McGarigal et al. 2017). This dataset, DSLland, is based on the Northeast Terrestrial Wildlife Habitat Classification System in the 2010 Ecological Systems Map (or ESM; TNC 2010). Several important additions relevant to coastal areas were made (noted in Lentz et al. 2015a), including road and train track misalignment corrections (source Open Street Map); replacement of National Wetlands Inventory estuarine data with estuarine and marine class data (National Wetlands Inventory 2013); replacement of ESM single-developed and agriculture classes with National Land Cover Dataset 2011 classes; and empirical derivations of streams and road crossings with high resolution data from the National Hydrography Dataset and Open Street map vector roads data. DSLland data defined the resolution $(30 \mathrm{~m} \times 30 \mathrm{~m})$ of our predictions, as they were intended to be used to support a parallel habitat modeling effort which similarly used these data (results at Nature's Network: https://naturesnetwork. $\operatorname{org} /$ ).

The $\mathrm{BN}$ used to generate $\mathrm{AE}$ and dynamic response likelihoods required two different implementations. AE was calculated by using a probabilistic implementation of a deterministic equation that subtracted RSLR from 2010 elevation. Bayesian inference was used to train the model on the geospatial co-occurrence of elevation and land cover datasets and their inherent correlation. For example, marshes and beaches tend to be found at lower elevations than 
Table 1 Reclassification of land cover types contained in the original land cover dataset (created by the Designing Sustainable Landscapes project; McGarigal et al. 2017) to broader land cover categories used in this study

\begin{tabular}{ll}
\hline $\begin{array}{l}\text { Land cover categories considered } \\
\text { in this study }\end{array}$ & McGarigal et al. (2017) Land cover class \\
\hline Marsh & $\begin{array}{c}\text { Salt and freshwater marshes, bogs, swamps, fens, wetland forests, intertidal aquatic beds, and } \\
\text { reefs } \\
\text { Dune and swale/sandy beach (including bluffs), marine and estuarine intertidal unconsolidated } \\
\text { shore }\end{array}$ \\
Reach & Rocky outcrops and shores, marine and estuarine intertidal rock bottom \\
Focky & All National Land Cover Dataset developed classes (open space, low, medium, and high \\
Developed & density), roads, active and abandoned railroad tracks
\end{tabular}

Classes included in each category are anticipated to respond similarly to sea-level rise (SLR) and in a manner that is ecologically and/ or morphologically distinct from the other general categories

forests and uplands. Doing so allowed better resolution of uncertainties tied to these data inputs and to reduce error (Lentz et al. 2019). The likelihood of inundation assigned to different land cover types compared AE with the generalized SLR tipping points (i.e. inundation thresholds) specific to the initial land cover types. This landcover-specific likelihood was based on a synthesis of published studies extensively documented in Lentz et al. (2015a, 2016). Expert knowledge was applied to fill information gaps on inundation likelihoods for land cover types where this information was unknown (e.g. rocky land cover types). Because land cover data are not updated in the model, inundation probability over time is based on the RSLR increment interacting with the initial land cover type.

\section{Reclassification of inundation likelihoods}

In this study, we expanded on Lentz et al. (2015a, b, 2016) to explore patterns of inundation relative to land cover diversity and composition with time. The work presented here is new in that we used existing information to infer where, when, and why changes that could lead to state shifts may be more likely in association with current land cover types across the region. We reclassified continuous inundation probabilities for every $30 \times 30 \mathrm{~m}$ landscape cell to probabilistic categories used by the IPCC (Mastrandrea et al. 2010). These categories included the following: very unlikely to be inundated (probability of inundation $(\mathrm{p})<0.10)$, unlikely to be inundated $(0.10<\mathrm{p}<0.33)$, as likely as not to be inundated $(0.33<\mathrm{p}<0.66)$, and likely to be inundated ( $p>0.66$ ). Under this classification, as likely as not indicates high uncertainty such that inundation or a dynamic response are nearly equally likely for that landscape cell (Mastrandrea et al. 2010). Although they are broad, using these uncertainty ranges allowed us to be conservative in our predictions of land cover change, particularly where land cover data are static in the model. By leveraging IPCC terminology, these ranges also allowed us to convey results in a widely accepted, approachable manner.

\section{Regional determination}

We evaluated the total area and percentage of the study area that fell into each of the four inundation likelihood categories over four intervals (2020s, 2030s, 2050s, and 2080s). Changes in inundation likelihoods through time were tracked by (i) determining the percentage of the region in each inundation likelihood range (i.e., very unlikely, unlikely, as likely as not, and likely to be inundated) for the 2020s as the baseline time period and (ii) subtracting those percentages from their respective likelihood categories in the 2030s, the 2050s, and, finally, the 2080s. Changes from the 2020s baseline decade to the 2030s were found to be negligible and are not reported in our results. Also, in this analysis, we focused on changes to land cover that was above-water as of the 2010 land cover dataset (McGarigal et al. 2017). Because more than half of the nearly $38,000 \mathrm{~km}^{2}$ regional study area 
in Lentz et al. (2015a, 2016) was considered subaqueous, we considered a reduced study area of $17,000 \mathrm{~km}^{2}$ in the present study.

To parse regional inundation resistance vs. vulnerability, we evaluated categorical inundation probabilities for the five land cover types shown in Table 1. We calculated the total and percentage area covered by the reclassified land cover type that fell into each categorical inundation likelihood in each of three study periods.

\section{Site-specific determination and diversity assessment}

To explore inundation resistance as it relates to land cover diversity and composition, we assessed patterns of inundation likelihood within 26 sites throughout the study area (Fig. 3). We selected sites with welldefined and publicly available geospatial boundaries and used these to subset the regional analysis (see Table S1 in Supporting Information). Because the regional analysis only considered land cover up to $10 \mathrm{~m}$ elevation, the extent of site-specific analyses covered all areas below $10 \mathrm{~m}$ elevation within the administrative boundary for the site. We repeated the regional analysis within each site boundary, calculating the total area and percentage of a given site that fell into each categorical inundation likelihood (i) within the entire site generally and (ii) within each of the five land cover types represented in the site. In the first case, we calculated inundation likelihoods as total and percentage areas for each study period. To gauge the propensity of a site for state shifts, we then tracked changes in inundation likelihoods through time by subtracting the percentage of the site likely to be inundated in the 2020s from the percentages likely to be inundated in the 2050s and 2080s. In the second case-where inundation likelihoods were assessed by land cover-inundation likelihoods were assessed for the 2020s only.

Finally, we examined potential correlations between categorical inundation likelihoods and land cover diversity at the 26 sites. In this analysis, 'land cover diversity' was used to indicate the number and proportion of land cover types within the site boundary up to the 10-m elevation contour. As demonstrated in Lentz et al. (2019) and Zinnert et al. (2017), elevation and land cover data in the coastal zone have an inherent correlation. For example, marshes and beaches tend to be low-lying, whereas, by comparison, upland environments occur at higher elevations. Therefore, we expected that areas of higher land cover diversity were also likely to contain a wider range of elevation distributions, which also will affect an area's overall likelihood of SLR inundation. We calculated land cover diversity according to the following diversity index (Turner et al. 2001):

$H=\frac{-\sum_{i=1}^{n} \rho_{i} \ln \left(\rho_{i}\right)}{\ln (s)}$

where $H$ is the diversity index, $\rho i$ is the proportion of the landscape occupied by cover type $i$, and $s$ is the number of land cover types present. Dividing by $\ln (s)$ ensures that $H$ is normalized to a range between zero and one, where higher values of $H$ indicate more diversity. This land cover diversity index (here, referred to it as Turner's diversity index) provided a straightforward means of rapid assessment of land cover heterogeneity and composition for our sites, and it is the landscape equivalent to Shannon's equitability index (Shannon 1948) for assessing species-level diversity within a site.

\section{Results}

Trends in inundation likelihoods

Of the $17,000 \mathrm{~km}^{2}$ of subaerial land in our regional study area, $56 \%$ was as likely as not to be inundated, and $44 \%$ was unlikely to be inundated in the baseline study period (2020s; Fig. 4a). Through time, shifts from more certain outcomes (i.e., likely or unlikely to be inundated) to more uncertain outcomes occurred; by the 2050 s, $58 \%$ of the study area was considered $a s$ likely as not to be inundated, a $2 \%$ increase in this category from the 2020s. By the 2080s, nearly $64 \%$ of the region was as likely as not to be inundated, an $8 \%$ increase in this category from the 2020s.

The majority of the 26 sites assessed in the study area contained coastal areas that were as likely as not to be inundated. For 20 sites, more than $50 \%$ of the study area was as likely as not to be inundated in the 2020s, and this area percentage increased by the 2080s (see Table S2 in Supporting Information). For the remaining six sites-all national wildlife refuges - the reverse was true; a greater proportion of these sites were considered unlikely to be inundated compared to 
as likely as not in the 2020s. Only five of these six sites retained this relationship by the 2080s (Table S2).

Inundation likelihood and land cover type

When assessed by land cover type, results reflected the wide variation in inundation likelihood expected from the distinct land cover categories as well as variation in how specific land cover types would respond through time. Sixty-five percent of the region characterized by rocky land cover types (e.g., headlands and bedrock shores; $1 \%$ of the $17,000 \mathrm{~km}^{2}$ study area; Fig. 4b) was likely or very likely to be inundated by the 2020s (Fig. 4c). This percentage increased to $76 \%$ by the 2080s (Fig. 4c). In contrast, beaches (covering 9\% of study area; Fig. 4b) and forests (covering $31 \%$ of study area; Fig. 4b) were less likely to be inundated. In the 2020 s, $92 \%$ of beaches and $65 \%$ of forests were unlikely to be inundated (Fig. 4c). The remaining $8 \%$ and $35 \%$ of beaches and forests, respectively, were as likely as not to be inundated, reflecting more limited response uncertainty to SLR impacts (Fig. 4c). However, this uncertainty increased by the 2080 s; $15 \%$ of beaches and forests that were considered unlikely to be inundated in the 2020s shifted to as likely as not to be inundated in the 2080s (Fig. 4c).

Response uncertainty was high for marshes (comprising $44 \%$ of the regional study area) and developed ( $27 \%$ of regional study area; Fig. 4b) land cover types. Sixty-five percent of marshes were as likely as not to be inundated in the 2020s, with the remaining $35 \%$ of marshes unlikely to be inundated (Fig. 4c). By the 2080s, these proportions shifted to $70 \%$ as likely as not and $30 \%$ unlikely to be inundated. Uncertainty was high for developed areas for all decades; $98 \%$ of developed areas were as likely as not to be inundated for the 2020s, and this trend held through the 2080s (Fig. 4c).

Given the differences in response predictions, the composition and diversity of specific land cover types comprising a given site appear related to the overall likelihood of inundation and rate of change of that likelihood potential through time (Figs. 5, 6). Sites that supported a higher percentage of forests and beaches generally had a higher percentage of area unlikely to be inundated in the 2020s $\left(\mathrm{R}^{2}=0.4\right.$ and 0.2 , respectively; Fig. 5). We also observed a slight positive relationship between proportion of a site comprised of marsh and the percentage of the site unlikely to be inundated by the 2020s $\left(\mathrm{R}^{2}=0.1\right.$; Fig. 5$)$. In contrast, sites with a high proportion of development had a smaller percentage area that was unlikely to be inundated $\left(\mathrm{R}^{2}=0.6\right)$ and were least likely to experience substantial shifts by the 2080s (Table S2) due to the high response uncertainty assigned to this category through time in our model.

Furthermore, within-site land cover diversity was moderately correlated $\left(\mathrm{R}^{2}=0.4\right.$; Fig. 6 a) with the total proportion of a site's area that had an unlikely inundation prediction. For sites with a high Turner's diversity index $(>0.4)$, a larger proportion of a given site's area was predicted to be unlikely to be inundated compared to those sites with a lower diversity index $(<0.2)$. For example, $38 \%$ of Cape Cod NS in Massachusetts-which contained all five land cover types and had a Turner's diversity index of 0.66-was unlikely to be inundated in the 2020s (Figs. 6, 7, Table S2). Similarly, $75 \%$ of Trustom Pond National Wildlife Refuge in Rhode Island - which contained all five land cover types and had a diversity index of 0.63 - was unlikely to be inundated in the 2020s (Fig. 6, Table S2). However, a greater proportion of diverse sites shifted from unlikely to be inundated in the 2020s to as likely as not to be inundated in the 2050s and 2080s compared to sites with lower diversity indices (Fig. 6b, Table S2).

Conversely, sites with the lowest diversity valuespredominantly developed cities in our analysistended to have smaller percentages of total area unlikely to be inundated (Fig. 6, Table S2). For example, Baltimore, Maryland, predominantly composed of development, had a diversity index of 0.05 ; only $3 \%$ of this site was unlikely to be inundated in the 2020s (Figs. 6, 7 Table S2). Four percent of Boston, Massachusetts-with a diversity index of 0.16 and predominantly composed of development-was unlikely to be inundated by the 2020s (Fig. 6, Table S2). Developed sites generally had smaller areas that shifted to more uncertain outcomes through time (i.e., from unlikely inundated to as likely as not or from likely inundated to as likely as not; Fig. 6, Table S2).

\section{Discussion}

Understanding where and at what point biogeomorphic changes that may result in state shifts could occur under future SLR scenarios provides an important 
A

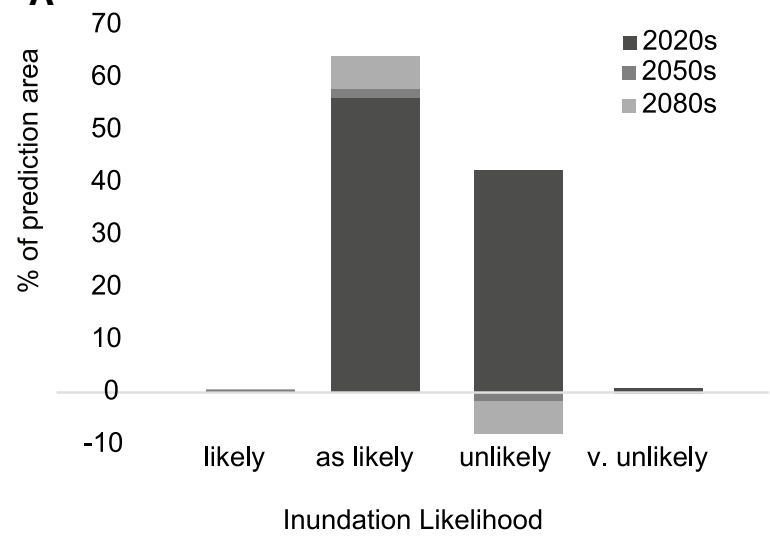

C

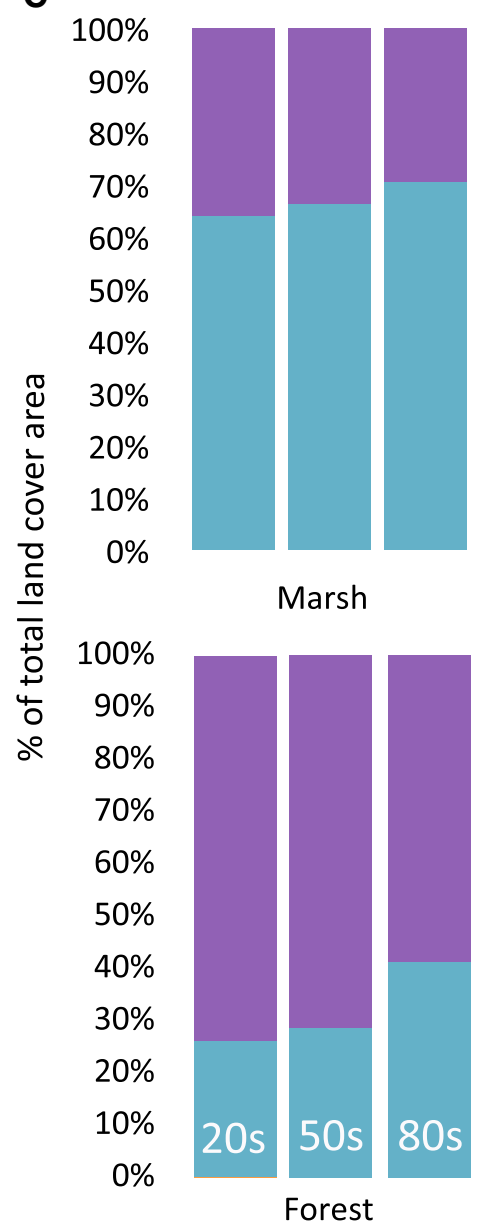

B
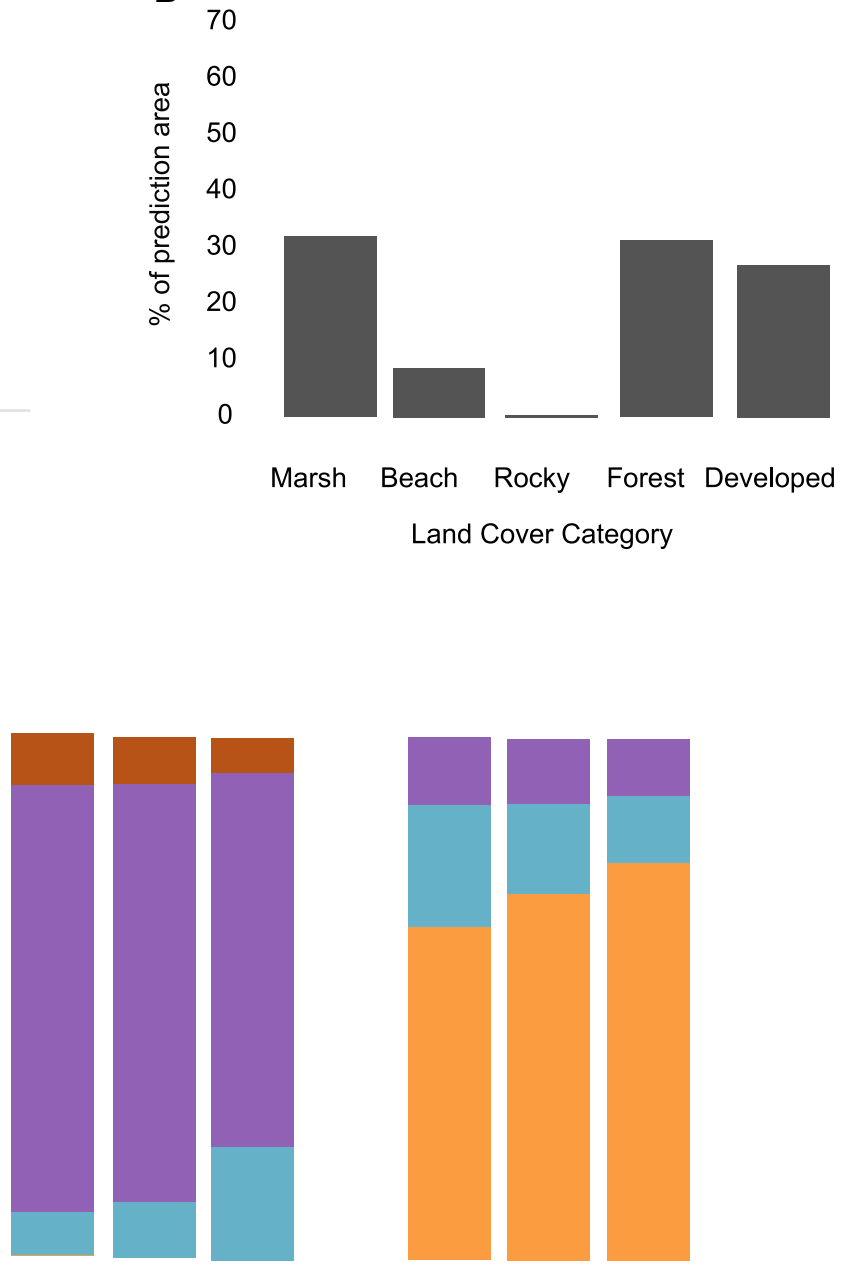

Beach

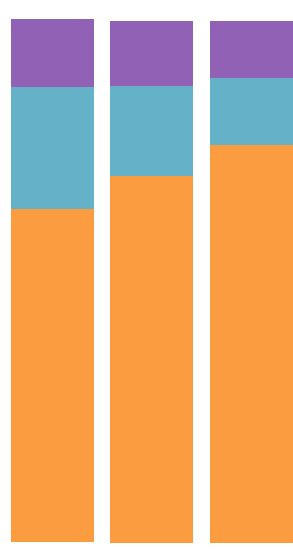

Rocky

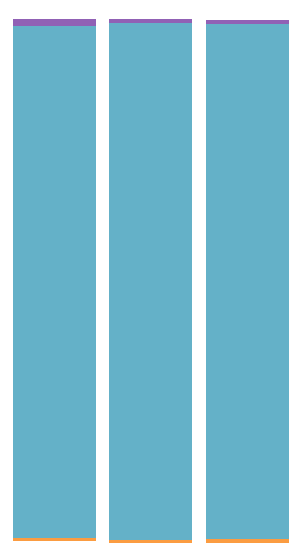

Developed

\section{Inundation Likelihood}

likely ( $p>0.66$ )

as likely as not $(0.33<p<0.66)$

— unlikely $(0.10<p<0.33)$

- v. unlikely $(p<0.10)$ 
4Fig. 4 a Percentage of the regional area falling in each inundation likelihood category for the SLR baseline ( 0 to $0.5 \mathrm{~m}$ or 2020s), and potential percentage shifts among categories under higher scenarios: 0.5 to $0.75 \mathrm{~m}$ or $2050 \mathrm{~s}$; and 0.75 to $2 \mathrm{~m}$ or 2080s. We further analyzed inundation likelihoods by $\mathbf{b}$ the land cover types that comprise the entire regional study area. c Illustrates the percentage area of each land cover type that was likely (probability of inundation $(p)>0.66)$, as likely as not $(0.66>p>0.33)$, unlikely $(0.33>p>0.10)$, and very unlikely $(p<0.10)$ to be inundated by sea-level rise in the 2020 s, 2050s, and 2080s

first-order application to support planning and management targets. In this assessment, we found most of our regional study area (56\%) is as likely as not to be inundated by the 2020 s, increasing to $58 \%$ by the 2050 s and $64 \%$ by the 2080 s. In other words, the baseline state includes considerable uncertainty around coastal evolution and landward migration of environments already, and land that was initially unlikely to inundate shows increasing uncertainty in response through time (Fig. 4a). Our purpose in setting likelihood ranges was to discretize uncertainty to vetted terminology in a manner that could be more meaningful and actionable. Therefore, it is important to note that, contrary to Mastrandrea et al. (2010) where likelihood terminology implies robustness in both evidence and degree of agreement, a shift from a more likely range to a more uncertain range in our outcomes implies that we are no longer as confident that an area will proceed to evolve in response to SLR as it has in the past. Our regional results suggest that the gradual press-disturbance of SLR will result in behaviors, including the increased potential for state shifts, that are difficult to predict at the landscape scale.

Embedded in these regional trends, however, are ecologic and geomorphic distinctions in land cover type, which inherently include natural processes and feedbacks that govern coastal response (Corenblit et al. 2011; Brantley et al. 2014; Lentz et al. 2016). These processes were initially accounted for in the literature synthesis and expert assessment in the original development of the BN (Lentz et al. 2015a and references therein). Beaches, marshes, and forests either possess natural mechanisms that allow them to respond to SLR or are associated with surrounding abiotic conditions that help to mitigate the effects of
Fig. 5 Plots illustrating the relationship between the total proportion of a given site characterized by a specific land cover type and the proportion of that site unlikely to be inundated by sea-level rise in the 2020s. $P$-values for the beach, rocky, and forest plots are less than 0.05 ; $p$-values for the marsh and developed plots are greater than 0.05 , suggesting that the latter have little relationship with a site's dynamic response propensity

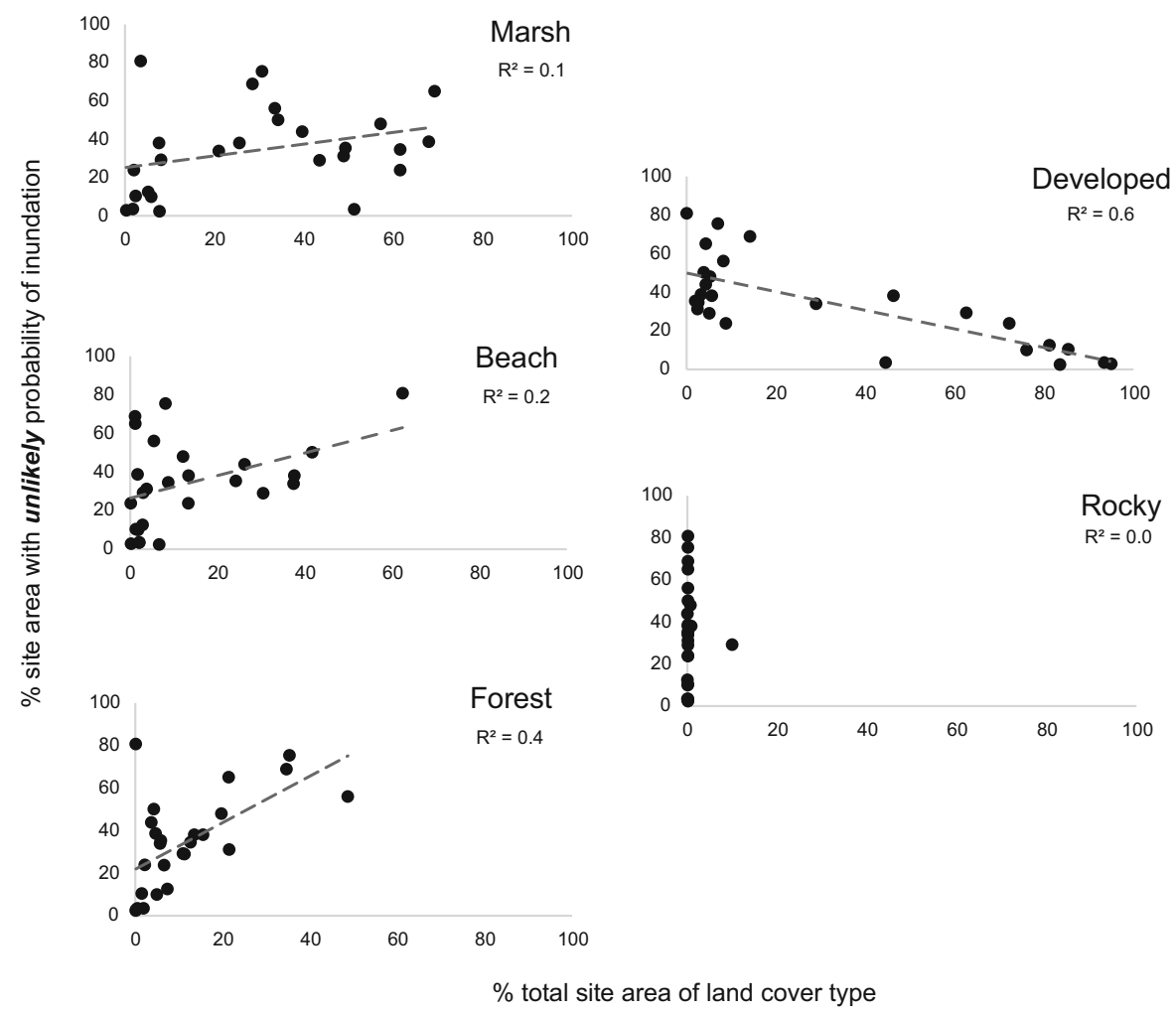


Fig. 6 Plots illustrating (a) the relationship between a site's diversity in land cover types (as measured by Turner's diversity index; Turner et al. 2001) and the total proportion of a site's area that is unlikely to be inundated in the 2020s; and b the percentage of area likely to change within these sites to a more uncertain category in the 2050s and the 2080s. Sites included federally protected national wildlife refuges (NWRs) and national seashores (NSs) as well as cities. In b, dashed lines between points show site-specific changes in inundation probabilities between time steps. Here, it can be noted that the total proportion of a site's area that is unlikely to be inundated in the 2050s declined by the 2080 s for some sites (typically NWRs and NSs), signaling an increase toward inundation likelihood

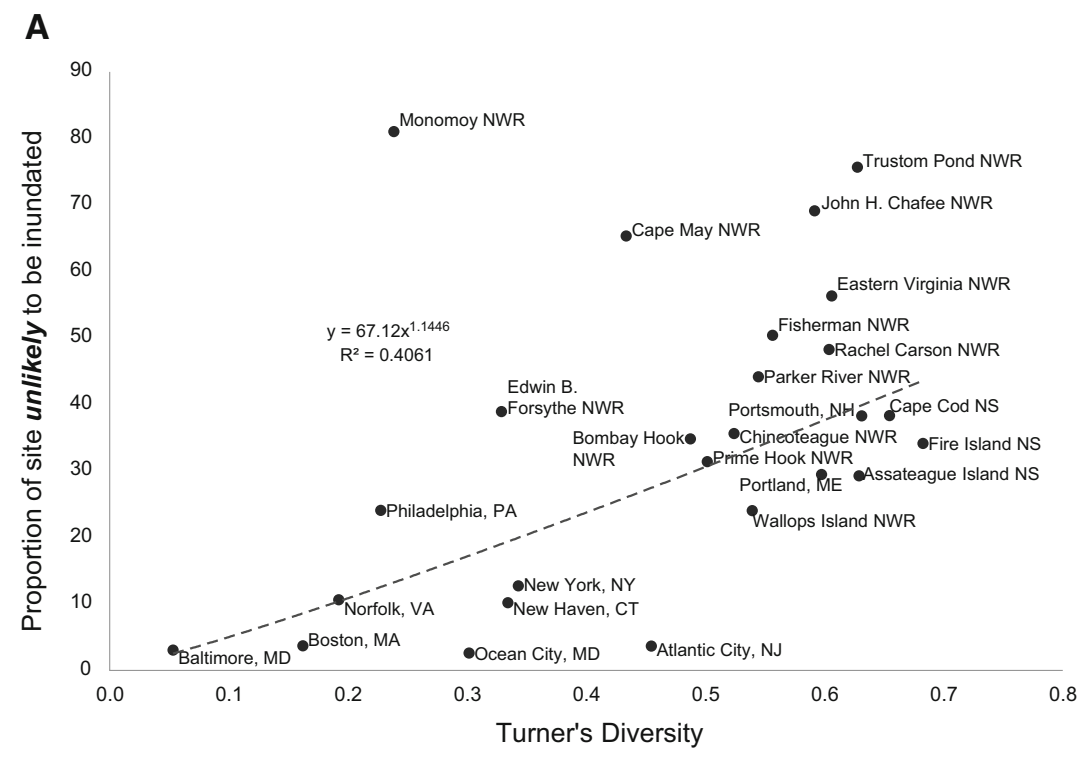

B

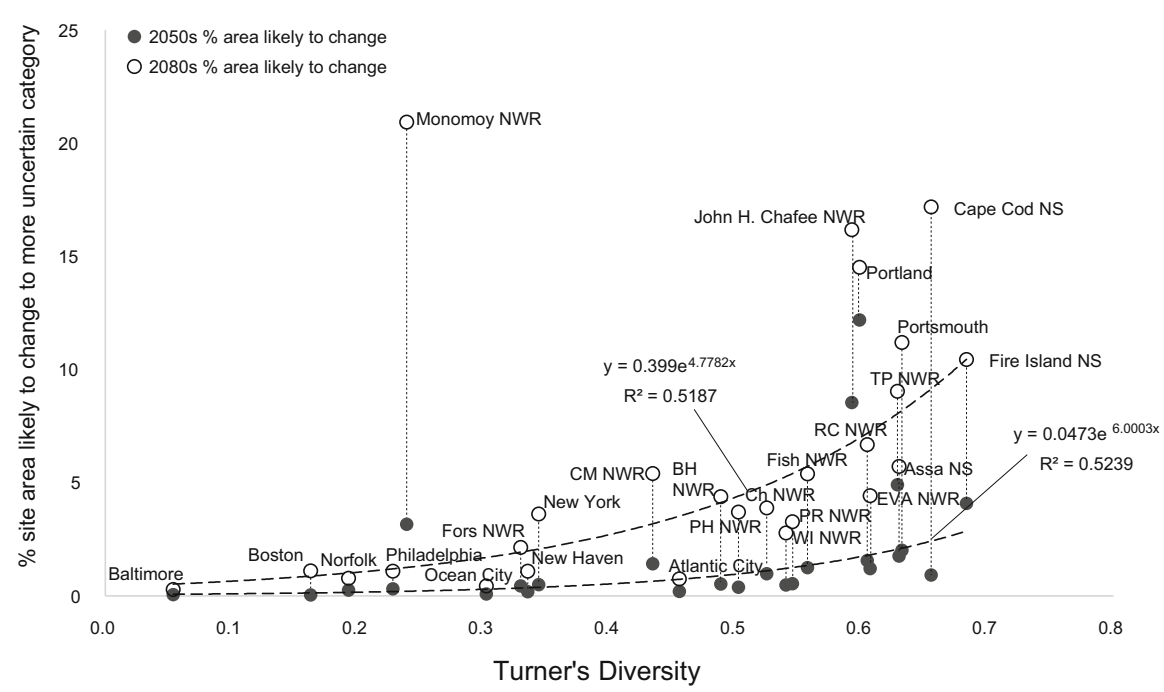

SLR. Marshes have a particularly high uncertainty in our model-65\% as likely as not to inundate-as we acknowledge the importance of regional variations (Lentz et al. 2015a). Marshes can vary widely in sediment supply and biomass production feedbacks Kirwan and Murray 2007; (Kirwan and Megonigal 2013; Raposa et al. 2017) as well as uncertainty in factors affecting landward migration, such as slope and infrastructure (Torio and Chmura 2013; Field et al. 2016). By contrast, forested uplands have a lower uncertainty in our model; $40 \%$ of all forested land cover was as likely as not to inundate and $60 \%$ was unlikely to inundate in the 2080s. Coastal forests are frequently associated with higher elevations and steeper slopes than marshes. In addition, forests tend to accumulate organic matter and to contain species that are longer-lived and better ecological competitors, making forests more resistant to canopy die-back, ecosystem state changes, and inundation than other land cover types (Brinson et al. 1995; Zinnert et al. 2016b). Beaches are perhaps the most dynamic environment in the coastal response model-92\% unlikely to inundate and only $8 \%$ as likely as not to inundate in the 2020s. Beaches respond over a variety 
A
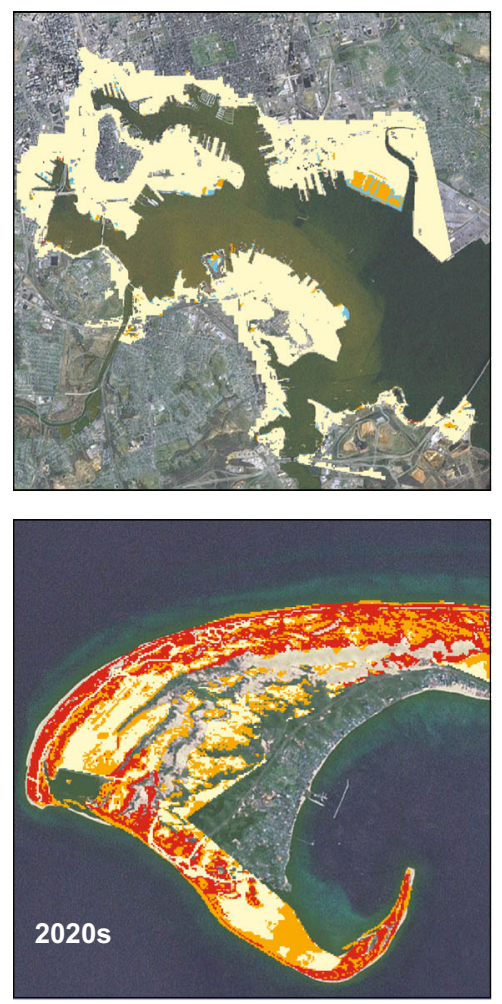
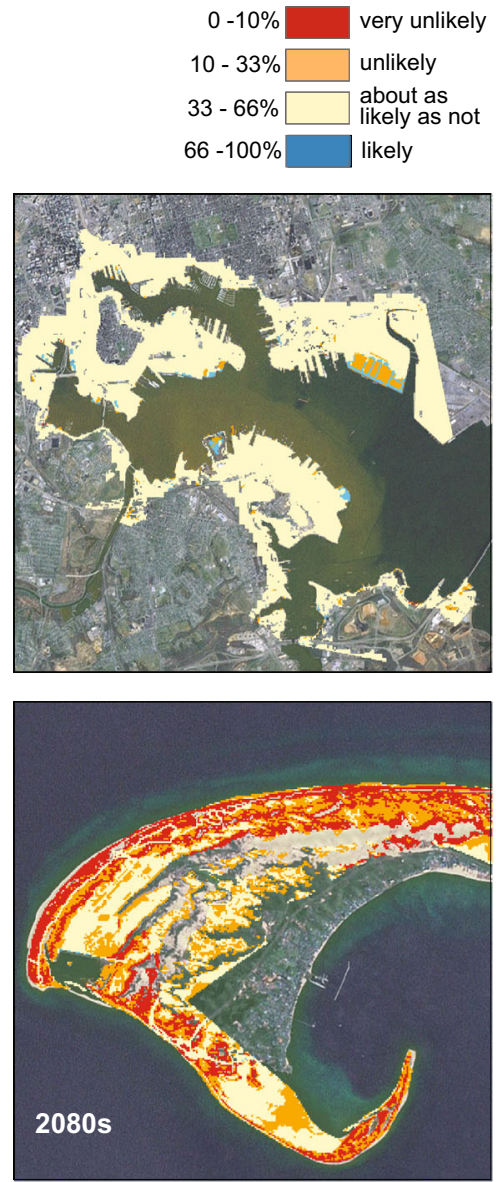
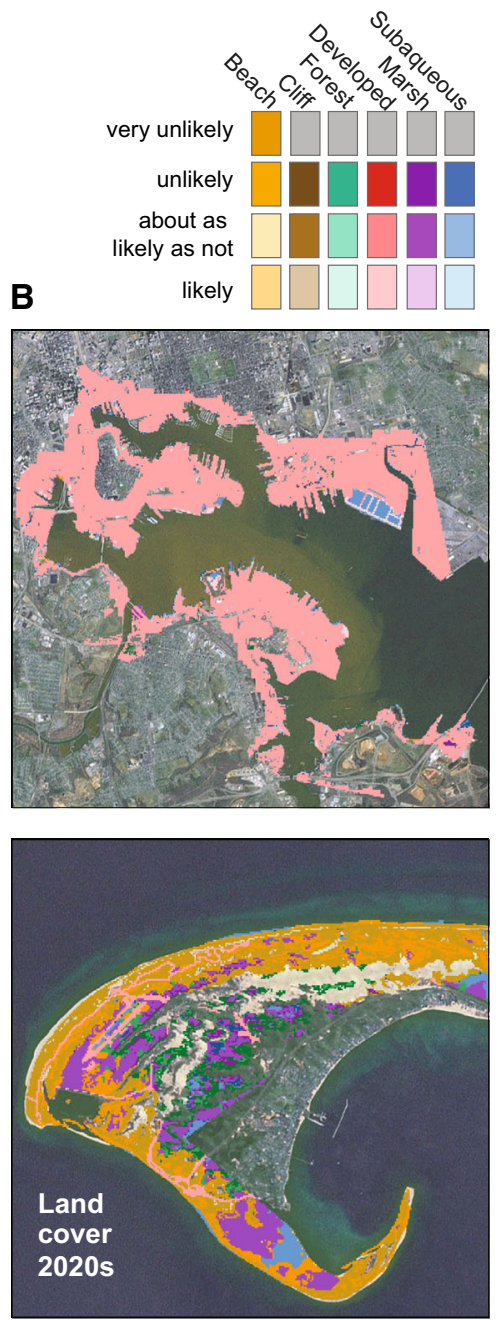

Fig. 7 Individual site likelihood predictions for Baltimore, Maryland (top) and Cape Cod National Seashore (bottom) as denoted in Fig. 2. a Coastal response predictions were grouped into probabilistic ranges reflecting each location's likelihood of

of timescales to wind and wave action (Leatherman 1979; Oertel 1985; Carter 1988; Davis Jr 1994), are stabilized by common types of beach vegetation (e.g., Ammophila breviligulata) adapted to periodic burial (Zinnert et al. 2017 and references therein), and evolve and migrate landward in response to longer-term drivers such as sediment supply and SLR (FitzGerald et al. 2008). It is additionally important to note that for forests, marshes, and beaches, surrounding land use patterns have the potential to directly affect the dynamic adaptability of either their physical characteristics or processes which affect them, such as by limiting migration due to development presence (i.e. being inundated in the 2020s and 2080s. b Inundation likelihoods were further grouped by the six different land cover types for the same example locations, with lighter colors showing greater likelihood of inundation

'coastal squeeze'; Doody 2004). The remaining land cover types—rocky shorelines and development — are associated with higher overall risks of inundation or greatest uncertainty because they lack biogeomorphic mechanisms or natural feedbacks that allow them to respond dynamically to SLR (Lentz et al. 2015a). However, human modifications or management responses have the capacity to alter shoreline change rates such inundation likelihood, at least over shortterm scales, is masked (e.g., Armstrong and Lazarus 2019). Consequently, rocky land cover had the highest percentage of area of any land cover type likely to be inundated by the 2020 s $(65 \%)$, while $98 \%$ of all 
developed areas were as likely as not to be inundated by the 2020 s due largely to uncertainty regarding future human behavior in the SLR response.

Although resolving process uncertainty via exceedance thresholds for different land cover types remains an important area of continued research (Kopp et al. 2016, 2019), examining the relative rates of future change for different coastal environments via likelihood ranges allows us to determine when SLR increases generally begin to outpace the rates at which land cover types are able to naturally adapt and, as a result, may approach state shifts (Hughes et al. 2013). For example, our results showed that, by the 2080s, shifts in beach and forest responses (from unlikely to as likely as not) increased more rapidly through time than other land cover types (Fig. 4c). Other studies have found that the amplification of the storm regime may further exacerbate the effects of accelerating SLR (Vitousek et al. 2017; Kopp et al. 2019), possibly leading to ecological 'surprises' as disturbances are compounded (Paine et al. 1998). For example, lowerlying beach and dune systems in Virginia are more vulnerable to chronic overwash, breaching, or disaggregation-shifting states from terrestrial to marine ecosystems - as storms move elevated water volumes and sediments over coastal systems (Vinent and Moore 2015; Goldstein and Moore 2016; Zinnert et al. 2016a). The increase in response uncertainty in our model, particularly for beaches and forests, corresponds with this increasing probability that biogeomorphic changes leading to state shifts could occur through time.

SLR response uncertainty was high for the remaining land cover types even as early as the 2020s, and uncertainty either increased moderately (for marshes, an increase of $5 \%$ of the total land cover area), changed negligibly (development), or was reduced (rocky) by the 2080s (Fig. 4c). As outlined earlier, the ability of marshes to adapt to RSLR is very site specific, as has been exemplified at a number of sites in the U.S. Northeast (Hill and Anisfield 2015; Beckett et al. 2016; e.g. Kolker et al. 2009; Raposa et al. 2017). Physical, process-based uncertainties are considerable at the outset for marshes due to local factors, and the moderate temporal shifts in our model results reflect increasing uncertainty in marsh adaptation that is largely attributable to local processes and conditions that our current framework does not resolve. Developed areas retain a high response uncertainty in our model through time to SLR, likely due largely to socioeconomic factors that influence coastal management actions and are difficult to weigh and predict through time (e.g. McNamara et al. 2011). The likelihood of inundation for rocky coasts, in contrast, is straightforward given they are unable to erode, migrate, or change at a rate that can keep pace with rising seas.

Site comparisons allowed us to assess how the composition and diversity of a site were associated with its predominant response to SLR. Sites with a higher land cover diversity had less area that was likely to be inundated compared to more developed sites with lower diversity both initially (2020s) and through time (2080s). These high-diversity sitesincluding national wildlife refuges and national seashores-were predominantly comprised of marshes, forests, and beach ecosystems, and, as outlined above, include biogeomorphic feedbacks that allow them evolve naturally in response to pulse/press drivers through a state change beyond simple inundation. The considerably larger amount of land area to change from unlikely to inundate to as likely as not in these sites points to a steadily diminishing inundation resistance with time that may suggest critical threshold exceedance, making these sites more vulnerable than they have been in the past to future coastal change drivers (Figs. 1, 6, 7). Highlighting where these changes are more probable can be used to direct and apply deterministic modeling efforts that can factor in site-specific conditions and parameters. By contrast, sites comprised primarily of development showed the potential for high vulnerability to widespread land loss via inundation. Only small portions of these sites are unlikely to inundate even as early as the 2020s (Fig. 6). Instead, most of these sites are as likely as not to inundate, reflecting a high level of uncertainty in human behavior and landscape response to even relatively low net increases in sea level. These findings demonstrate how critical it is to account for and better understand the role of landscape composition, complexity, and human impacts under future climatedriven pulse/press scenarios as in Folke et al. (2004).

Here it is important to note the inherent relationship between coastal land cover and elevation variables, wherein elevation acts as an important control on land cover distributions (Zinnert et al. 2017; Lentz et al. 2019). For example, sites that supported a higher percentage of forests also had a higher percentage area 
that was unlikely to be inundated (Fig. 5); however, sites with forests also tend to contain higher elevation zones that make those sites less vulnerable to SLR (Zinnert et al. 2016b; Lentz et al. 2019). The correlated relationship between land cover, elevation zone, and SLR vulnerability makes it difficult to separate whether it's the higher elevations or ecosystem feedbacks that make a site better able to respond dynamically to SLR-although it is likely that both affect inundation vulnerability through time (Corenblit et al. 2011; Brantley et al. 2014; Zinnert et al. 2017 and references therein).

Furthermore, our results suggest that land cover diversity may also influence a site's response to SLR. Other studies have shown that high levels of ecological diversity in habitats and species assemblages have a stabilizing effect on the physical landscape (Reinhardt et al. 2010), particularly in coastal environments (Stallins 2006). This may be due to the inherent relationship with elevation as well as dual directionality in coastal biogeomorphic processes. In coastal environments, physical processes (e.g., wave run-up) constrain the environment in which biological evolution occurs-and therefore shape the biotic community_while the biotic community modifies and 'engineers' the physical environment to enhance survival (Zinnert et al. 2017; Reinhardt et al. 2010). High biodiversity also tends to stabilize aggregate ecosystem properties (Loreau and de Mazancourt 2013) and is critical for an ecosystem's adaptive capacity (Elmqvist et al. 2003). As the number of species in the environment increases, synchrony in responses to environmental change decreases in what is termed 'response diversity', and asynchrony always has a stabilizing effect in complex ecological networks (Elmqvist et al. 2003; Loreau and de Mazancourt 2013). Although specific state changes are not directly accounted for in our model, we posit that, in conjunction with elevation, a diverse array of substrates and vegetation communities may promote biogeomorphological response diversity, allowing coastal sites with high land cover diversity to respond dynamically to SLR as opposed to being inundated. However, as with elevation, it is difficult to separate the effect of land cover diversity versus land cover composition on inundation vulnerability in this study. The more diverse sites-namely NWRs and NSs-were more likely to contain land cover types that exhibit dynamic responses to SLR than the more homogenous cities composed almost entirely of developed land cover. Therefore, it is unknown whether more diverse sites are less likely to be inundated because of land cover diversity (and corresponding elevation variation) per se or land cover composition (or some combination). Additional work is needed to isolate these influences.

Absent more specificity on process-based biogeomorphologic changes, through the application of the likelihood ranges of Mastrandrea et al. (2010), we sought to provide an established numerical range and accompanying terminology to discretize our continuous probabilistic outcomes and assess trends at the regional-scale related to diversity and composition. Studies have shown that using ranges with an accompanying terminology can be useful to ensure more consistent interpretation of uncertainties (e.g. Budescu et al. 2012), although we also note the numerical ranges are so wide-particularly the as likely as not range- - this undoubtedly results in some information loss, wherein the steady trend of inundation likelihood through time is less clear. We suggest, however, this wider range helps to ensure our results are appropriately conservative given the limited ability of our model to resolve local dynamics and coastal processes, as well as static input of land cover as already noted. Additionally, we must note that shifts among discretized ranges relate to the definition of the specified range; data-derived ranges, such as credible intervals, may reveal more nuanced trends and distinctions in regional-scale dynamics, albeit without the uncertainty terminology association we found advantageous in this approach.

In providing a first order assessment of inundation resistance across dynamic coastal landscapes, we demonstrate an application of model outcomes that can help decision-makers highlight where future vulnerability and corresponding management strategies are best employed. Once initiated, the shift of an equilibrium baseline to an alternate state or open water could occur quickly by reaching a tipping point (over seasons or years) or more slowly via a critical threshold (over decades or centuries; Fig. 1). From there, amplified change drivers prevent ecosystems from easily reverting to their former states (Moore et al. 2010; Wang and Temmerman 2013; EslamiAndergoli et al. 2015; Kirwan et al. 2016; Philips 2018, Philips 2018). Without biogeomorphic ability to adapt, urban areas will require targeted management strategies to address flooding of properties, 
infrastructure, and businesses-problems that will be amplified by storms (Knutson et al. 2010). By contrast, sites with more complex biogeomorphic composition or diversity will require ongoing monitoring to account for gradual dynamic changes and to identify critical thresholds. Here, adaptive management with a strong monitoring component may be the best strategy to deal with (i) land and property loss due to erosion or increasing overwash frequency or (ii) changes in available habitat types or land cover transitions (Fischman et al. 2014), such as shifts from agricultural land to wetlands (Voutsina et al. 2015).

Under updated SLR scenarios that account for improved understanding of ice-sheet collapse (Ignéczi et al. 2016; Sweet et al. 2017), we expect inundation thresholds will be reached sooner, regardless of land cover type or site-specific factors. We expect that SLR-driven non-equilibrium behavior will be longlasting (Hughes et al. 2013) and lead to no-analog communities (Williams and Jackson 2007) with a host of social, economic, and ecological implications (Arkema et al. 2013; Neumann et al. 2015a; Hauer et al. 2016; Leonard et al. 2017). Therefore, identifying where and when biogeomorphic state shifts are more likely to occur across the regional coastal landscape-even if the shift is associated with high uncertainty-can be used to broadly identify where hedging, scenario planning, and adaptive management strategies are best employed (Maler 2000).

Acknowledgments This research was funded by the U.S. Geological Survey Coastal and Marine Hazards and Resources Program. We thank Neil Ganju for early reviews and discussion of this manuscript, as well as the comments of several anonymous reviewers. Any use of trade, firm, or product names is for descriptive purposes only and does not imply endorsement by the US Government.

Open Access This article is licensed under a Creative Commons Attribution 4.0 International License, which permits use, sharing, adaptation, distribution and reproduction in any medium or format, as long as you give appropriate credit to the original author(s) and the source, provide a link to the Creative Commons licence, and indicate if changes were made. The images or other third party material in this article are included in the article's Creative Commons licence, unless indicated otherwise in a credit line to the material. If material is not included in the article's Creative Commons licence and your intended use is not permitted by statutory regulation or exceeds the permitted use, you will need to obtain permission directly from the copyright holder. To view a copy of this licence, visit http://creativecommons.org/licenses/by/4.0/.
Author contributions EEL, ERT, and NGP designed the study; EEL and NGP conducted analysis; and EEL and SLZ drafted the initial version of the manuscript. All authors discussed results and contributed to later versions of the manuscript.

Availability of data and material The original data used to conduct this analysis are available in: Lentz, E.E., Stippa, S.R., Thieler, E.R., Plant, N.G., Gesch, D.B., and Horton, R.M. 2015, Coastal landscape response to sea-level rise assessment for the northeastern United States (ver. 2.0., December 2015): U.S. Geological Survey data release, https://doi.org/10.5066/ F73J3B0B.

\section{References}

Ahnert F (1994) Equilibrium, scale, and inheritance in geomorphology. Geomorphology 11(2):125-140

Arkema KK, Guannel G, Verutes G, Wood SA, Guerry A, Ruckelshaus M, Kareiva P, Lacayo M, Silver JM (2013) Coastal habitats shield people and property from sea-level rise and storms. Nat Clim Chang 3(10):913-918

Armstrong S, Lazarus E (2019) Masked shoreline erosion at large spatial scales as a collective effect of beach nourishment. Earth's Future 7(2):74-84

Arns A, Wahl T, Dangendorf S, Jensen J (2015) The impact of sea-level rise on storm surge and water levels in the northern part of the German Bight. Coast Eng 96:118-131

Bamber JL, Aspinall WP (2013) An expert judgement assessment of future sea level rise from the ice sheets. Nat Clim Change 3(4):424-427

Beckett L, Baldwin A, Kearney M (2016) Tidal marshes across a Chesapeake Bay subestuary are not keeping up with sealevel rise. PLoS ONE 11(7):e0159753

Beisner B, Haydon D, Cuddington K (2003) Alternative stable states in ecology. Front Ecol Environ 1(7):376-382

Brantley S, Bissett S, Young D, Wolner C, Moore L (2014) Barrier island morphology and sediment grain size inhibit the recovery of dune building grasses following storm induced overwash. PLoS ONE 9 (art. e0104747).

Brinson M, Christian R, Blum L (1995) Multiple states in the sea-level induced transition from terrestrial forest to estuary. Estuaries 18(4):648-659

Brooks S, Spencer T, Christie E (2017) Storm impacts and shoreline recovery: mechanisms and controls in the southern North Sea. Geomorphology 283:48-60

Budescu D, Por H, Broomell S (2012) Effective communication of uncertainty in the IPCC reports. Clim Chang 113:181-200

Carter R (1988) Coastal environments: an introduction to the physical, ecological, and cultural systems of coastlines. Academic Press Inc., San Diego

Church JA, Clark PU, Cazenave A, Gregory JM, Jevrejeva S, Levermann A, Merrifield MA, Milne GA, Nerem RS, Nunn PD, Payne AJ (2013) Sea-level change. In: Stocker T, Qin D, Plattner G-K, Midgley P (eds) Climate Change 2013the physical science basis. Contribution of Working Group I to the Fifth Assessment Report of the Intergovernmental 
Panel on Climate Change. Cambridge University Press, Cambridge, UK, pp 1137-1216

Cooper J, McKenna J, Jackson D, O’Connor M (2007) Mesoscale coastal behavior related to morphological self-adjustment. Geology 35(2):187-190

Corenblit D, Baas A, Bornette G, Darrozes J, Delmotte S, Francis R, Gurnell A, Julien F, Naiman R, Steiger J (2011) Feedbacks between geomorphology and biota controlling Earth surface processes and landforms: a review of foundation concepts and current understandings. Earth Syst Rev 106:307-331

Davis R Jr (ed) (1994) Geology of Holocene barrier island systems. Springer, Berlin

Donohue I, Hillebrand H, Montoya JM, Petchey OL, Pimm SL, Fowler MS, Healy K, Jackson AL, Lurgi M, McClean D, O'Connor NE (2016) Navigating the complexity of ecological stability. Nature 19(9):1172-1185

Doody J (2004) 'Coastal squeeze'-an historical perspective. J Coast Conserv 10:129-138

Elmqvist T, Folke C, Nyström M, Peterson G, Bengtsson J, Walker B, Norberg J (2003) Response diversity, ecosystem change, and resilience. Front Ecol Environ 1(9):488-494

Eslami-Andergoli L, Dale P, Knight J, McCallum H (2015) Approaching tipping points: a focussed review of indicators and relevance to managing intertidal ecosystems. Wetl Ecol Manag 23(5):791-802

Feagin R, Figlus J, Zinnert J, Sigren J, Martinez M, Silva R, Smith W, Cox D, Young D, Carter G (2015) Going with the flow or against the grain? The promise of vegetation for protecting beaches, dunes, and barrier islands from erosion. Front Ecol Environ 13:203-210

Field C, Gjerdrum C, Elphick C (2016) Forest resistance to sealevel rise prevents landward migration of tidal marsh. Biol Conserv 201:363-369

Fischman RL, Meretsky VJ, Babko A, Kennedy M, Liu L, Robinson M, Wambugu S (2014) Planning for adaptation to climate change: lessons from the U.S. National Wildlife Refuge System. Bioscience 64(11):993-1005

FitzGerald D, Fenster M, Argow B, Buynevich I (2008) Coastal impacts due to sea-level rise. Annu Rev Earth Planet Sci 36:601-647

Folke C, Carpenter S, Walker B, Scheffer M, Elmqvist T, Gunderson L, Holling CS (2004) Regime shifts, resilience, and biodiversity in ecosystem management. Annu Rev Ecol Evol Syst 35:557-581

Gedan K, Kirwan M, Wolanski E, Barbier E, Silliman B (2011) The present and future role of coastal wetland vegetation in protecting shorelines: answering recent challenges to the paradigm. Clim Chang 106(1):7-29

Gesch DB (2007) The national elevation dataset. In: Maune DF (ed) Digital elevation model technologies and applications-The DEM users manual, 2ndd edn. American Society for Photogrammetry and Remote Sensing, Bethesda, pp 99-118

Goddard P, Yin J, Griffies S, Zhang S (2015) An extreme event of sea-level rise along the Northeast coast of North America in 2009-2010. Nat Commun 6:1-9

Goldstein E, Moore L (2016) Stability and bistability in a onedimensional model of coastal foredune height. J Geophys Res Earth Surf 121:964-977
Harris M, Gayes P, Kindinger J, Flocks J, Krantz D, Donovan P (2005) Quaternary geomorphology and modern coastal development in response to an inherent geologic framework: an example from Charleston, South Carolina. J Coast Res 21(1):49-64

Hauer M, Evans J, Mishra D (2016) Millions projected to be at risk from sea-level rise in the continental United States. Nat Clim Chang 6:691-695

Hill T, Anisfield S (2015) Coastal wetland response to sea level rise in Connecticut and New York. Estuaries Coast Shelf Sci 163:185-193

Hinkel J, Lincke D, Vafeidis AT, Perrette M, Nicholls RJ, Tol RS, Marzeion B, Fettweis X, Ionescu C, Levermann A (2014) Coastal flood damage and adaptation costs under 21st century sea-level rise. Proc Natl Acad Sci USA 111(9):3292-3297

Hino M, Field C, Mach K (2017) Managed retreat as a response to natural hazard risk. Nat Clim Chang 7:364-370

Holling C (1973) Resilience and stability of ecological systems. Annu Rev Ecol Syst 4:1-23

Houser C, Wernette P, Rentschlar E, Jones H, Hammond B, Trimble S (2015) Post-storm beach and dune recovery: implications for barrier island resilience. Geomorphology 234:54-63

Hughes T, Linares C, Dakos V, van de Leemput I, van Nes E (2013) Living dangerously on borrowed time during slow, unrecognized regime shifts. Trends Ecol Evol 28:149-155

Igneczi A, Sole A, Livingstone S, Leeson A, Fettweis X, Selmes N, Gourmelen N, Briggs K (2016) Northeast sector of the Greenland Ice Sheet to undergo the greatest inland expansion of supraglacial lakes during the 21 st century. Geophys Res Lett 43:9729-9738

Kirwan M, Megonigal J (2013) Tidal wetland stability in the face of human impacts and sea-level rise. Nature 504:53-60

Kirwan M, Murray A (2007) A coupled geomorphic and ecological model of tidal marsh evolution. Proc Natl Acad Sci USA 104(15):6118-6122

Kirwan M, Temmerman S, Skeehan E, Guntenspergen G, Fagherazzi S (2016) Overestimation of marsh vulnerability to sea level rise. Nat Clim Chang 6:253-260

Knutson TR, McBride JL, Chan J, Emanuel K, Holland G, Landsea C, Held I, Kossin JP, Srivastava AK, Sugi M (2010) Tropical cyclines and climate change. Nat Geosci 3(3): 157-163

Kolker A, Goodbred S, Hameed S, Cochran J (2009) Highresolution records of the response of coastal wetland systems to long-term and short-term sea-level variability. Estuaries Coast Shelf Sci 84(4):493-508

Kopp R (2013) Does the Mid-Atlantic United States sea level acceleration hot spot reflect ocean dynamic variability? Geophys Res Lett 40(15):3981-3985

Kopp RE, Horton RM, Little CM, Mitrovica JX, Oppenheimer M, Rasmussen DJ, Strauss BH, Tebaldi C (2014) Probabilistic 21 st and 22 nd century sea-level projections at a global network of tide-gauge sites. Earth's Future 2(8):283-406

Kopp RE, Kemp AC, Bittermann K, Horton BP, Donnelly JP, Gehrels WR, Hay CC, Mitrovica JX, Morrow ED, Rahmstorf S (2016) Temperature-driven global sea-level 
variability in the Common Era. Proc Natl Acad Sci USA 113(11):E1434-E1441

Kopp R, Gilmore E, Little C, Lorenzo-Trueba J, Ramenzoni V, Sweet W (2019) Usable science for managing the risks of sea-level rise. Earth's Future 7(12):1235-1269

Leatherman S (ed) (1979) Barrier Islands: from the Gulf of St. Lawrence to the Gulf of Mexico. Academic Press, New York

Leatherman S (2001) Social and economic costs of sea level rise. Int Geophys 75:181-223

Lentz E, Plant N, Thieler E (2019) Relationships between regional coastal land cover distributions and elevation reveal data uncertainty in a sea-level rise impacts model. Earth Surf Dyn 7:429-438

Lentz E, Stippa S, Thieler E, Plant N, Gesch D, Horton R (2015a) Evaluating coastal landscape response to sea-level rise in the northeastern United States-approach and methods. U.S. Geological Survey Open File Report 2014-1252. Available at https://doi.org/10.3133/ ofr20141252.26

Lentz EE, Stippa SR, Thieler ER, Plant NG, Gesch DB, Horton RM (2015b) Coastal landscape response to sea-level rise assessment for the northeastern United States (ver. 2.0., December 2015): U.S. Geological Survey data release. https://doi.org/10.5066/F73J3B0B

Lentz E, Thieler E, Plant N, Stippa S, Horton R, Gesch D (2016) Evaluation of dynamic coastal response to sea-level rise modifies inundation likelihood. Nat Clim Chang 6(7):1-6

Leonard P, Sutherland R, Baldwin R, Fedak D, Carnes R, Montgomery A (2017) Landscape connectivity losses due to sea-level rise and land use change. Anim Conserv 20:80-90

Leonardi N, Fagherazzi S (2014) How waves shape salt marshes. Geology 42(10):887-890

Loreau M, de Mazancourt C (2013) Biodiversity and ecosystem stability: a synthesis of underlying mechanisms. Ecol Lett 16:106-115

Lorenzo-Trueba J, Ashton A (2014) Rollover, drowning, and discontinuous retreat: distinct modes of barrier response to sea-level rise arising from a simple morphodynamic model. J Geophys Res 119(4):779-801

Maler K (2000) Development, ecological resources and their management: a study of complex dynamic systems. Eur Econ Rev 44:645-665

Marcy D, Brooks W, Draganov K, Hadley B (2011) Flooding impacts. In: Wallendorf L, Jones C, Ewing L, Battalio B (eds) Proceedings of the 2011 Solutions to Coastal Disasters Conference. American Society of Civil Engineers, Reston, VA, pp 474-490

Marzion B, Jarosch AH, Hofer M (2012) Past and future sealevel change from the surface mass balance of glaciers. Cryosphere 6(6):1295-1322

Mastrandrea MD, Field CB, Stocker TF, Edenhofer O, Ebi KL, Frame DJ, Held H, Kriegler E, Mach KJ, Matschoss PR, Plattner GK (2010) Guidance note for lead authors of the IPCC Fifth Assessment report on consistent treatment of uncertainties. https://www.ipcc.ch. In: (IPCC) I. P. o. C. C. (ed).

McGarigal K, Compton B, Plunkett E, Deluca W, Grand J (2017) Designing sustainable landscapes: project overview. Report to the North Atlantic Conservation
Cooperative, U.S. Fish and Wildlife Service, Northeast Region. University of Massachusetts, Amherst, Amherst, MA, p 53

McGlathery K, Reidenbach M, D’Odorico P, Fagherazzi S, Pace M, Porter J (2013) Nonlinear dynamics and alternative stable states in shallow coastal systems. Oceanography 26:220-231

McNamara D, Murray A, Smith M (2011) Coastal sustainability depends on how economic and coastline responses to climate change affect each other. Geophys Res Lett 38(7):1-5

Moore L, List J, Williams S, Stolper D (2010) Complexities in barrier island response to sea level rise: insights from numerical model experiments, North Carolina Outer Banks. J Geophys Res Earth Surf 115:1-27

National Oceanic and Atmospheric Administration National Geophysical Data Center, U.S. coastal relief model: National Oceanic and Atmospheric Administration National Geophysical Data Center Web page, last Accessed 9 June 2014 at https://www.ngdc.noaa.gov/mgg/ coastal/crm.html.

Neumann B, Vafeidis A, Zimmermann J, Nicholls R (2015a) Future coastal population growth and exposure to sea-level rise and coastal flooding-a global assessment. PLoS ONE 10(3): 0118571

Neumann JE, Emanuel K, Ravela S, Ludwig L, Kirshen P, Bosma K, Martinich J (2015b) Joint effects of storm surge and sea-level rise on US Coasts: new economic estimates of impacts, adaptation, and benefits of mitigation policy. Clim Chang 129(1-2):337-349

Oertel G (1985) The barrier island system. Mar Geol 63(1-4):1-18

Paine R, Tegner M, Johnson E (1998) Compounded perturbations yield ecological surprises. Ecosystems 1:535-545

Pelletier JD, Brad Murray A, Pierce JL, Bierman PR, Breshears DD, Crosby BT, Ellis M, Foufoula-Georgiou E, Heimsath AM, Houser C, Lancaster N (2015) Forecasting the response of Earth's surface to future climatic and land use changes: a review of methods and research needs. Earth's Future 3(7):220-251

Philips J (2018) Coastal wetlands, sea-level, and the dimensions of geomorphic resilience. Geomorphology 305:173-184

Phillips J (2018) Environmental gradients and complexity in coastal landscape response to sea level rise. CATENA 169:107-118

Plant N, Thieler E, Passeri D (2016) Coupling centennial-scale shoreline change to sea-level rise and coastal morphology in the Gulf of Mexico using a Bayesian network. Earth's Future 4:143-158

Radić V, Bliss A, Beedlow AC, Hock R, Miles E, Cogley JG (2013) Regional and global projections of twenty-first century glacier mass changes in response to climate scenarios from global climate models: Clim Dy 42(1-2):37-58

Raposa K, Weber R, Ekberg M, Ferguson W (2017) Vegetation dynamics in Rhode Island salt marshes during a period of accelerating and extreme sea level rise. Estuaries Coasts 40:640-650

Reinhardt L, Jerolmack D, Cardinale B, Vanacker V, Wright J (2010) Dynamic interactions of life and its landscape: feedbacks at the interface of geomorphology and ecology. Earth Surf Proc Land 35:78-101 
Roelvink D, Reniers A, van Dongeren A, van de Thiel VJ, McCall R, Lescinski J (2009) Modelling storm impacts on beaches, dunes, and barrier islands. Coast Eng 56(11-12):1133-1152

Sallenger A (2000) Storm impact scale for barrier islands. J Coast Res 16(3):890-895

Scheffer M, Carpenter SR, Lenton TM, Bascompte J, Brock W, Dakos V, Van de Koppel J, Van de Leemput IA, Levin SA, Van Nes EH, Pascual M (2012) Anticipating critical transitions. Science 338(6105):344-348

Schneider S (2004) Abrupt non-linear climate change, irreversibility, and surprise. Glob Environ Chang 14:245-258

Sella GF, Stein S, Dixon TH, Craymer M, James TS, Mazzotti S, Dokka RK (2007) Observation of glacial isostatic adjustment in "stable" North America with GPS. Geophys Res Lett 34(2):L02306;6

Shannon C (1948) A mathematical theory of communication. Bell Syst Tech J 27:379-423 and 623-656

Sherwood C, Long J, Dickhudt P, Dalyander P, Thompson D, Plant N (2014) Inundation of a barrier island (Chandeleur Islands, Louisiana, USA) during a hurricane: observed water-level gradients and modeled seaward sand transport. J Geophys Res 119(7):1498-1515

Stallins J (2005) Stability domains in barrier island dune systems. Ecol Complex 2:410-430

Stallins J (2006) Geomorphology and ecology: unifying themes for complex systems in biogeomorphology. Geomorphology 77:206-216

Strauss B, Ziemlinski R, Weiss J, Overpeck J (2012) Tidally adjusted estimates of topographic vulnerability to sea level rise and flooding for the contiguous U.S. Environ Res Lett $7: 1-12$

Sweet W, Dusek G, Obeyesekera J, Marra J (2018) Patterns and projections of high tide flooding along the U.S. coastline using a common impact threshold. NOAA Technical Report NOS CO-OPS 086. National Oceanic and Atmospheric Administration, Silver Spring, MD

Sweet W, Kopp R, Weaver C, Obeysekera J, Horton R, Thieler E, Zervas C (2017) Global and regional sea level rise scenarios for the United States. NOAA technical report NOS CO-OPS 083. National Oceanic and Atmospheric Administration, Silver Spring, MD, p 75
Sweet W, Park J (2014) From the extreme to the mean: acceleration and tipping points of coastal inundation from sea level rise. Earth's Future 2:579-600

Torio D, Chmura G (2013) Assessing coastal squeeze of tidal wetlands. J Coast Res 29(5):1049-1061

Taylor KE, Stouffer RJ, Meehl GA (2012) An overview of CMIP5 and the experiment design. Bull Am Meteorol Soc 93(4):485-498

Turner M, Gardner R, O’Neill R (2001) Landscape ecology in theory and practice. Springer-Verlag, New York

Vinent O, Moore L (2015) Barrier island bistability induced by biophysical interactions. Nat Clim Chang 5:158-162

Vitousek S, Barnard P, Fletcher C, Frazer N, Erikson L, Storlazzi C (2017) Doubling of coastal flooding frequency within decades due to sea-level rise. Sci Rep 7:1-9

Voutsina N, Seliskar D, Gallagher J (2015) The facilitative role of Kosteletzkya pentacarpos in transitioning coastal agricultural land to wetland during sea level rise. Estuaries Coasts 38:35-44

Wang C, Temmerman S (2013) Does biogeomorphic feedback lead to abrupt shifts between alternative landscape states?: an empirical study on intertidal flats and marshes. J Geophys Res Earth Surf 118:229-240

Williams J, Jackson S (2007) Novel climates, no-analog communities, and ecological surprises. Front Ecol Environ 5(9):475-482

Zervas C, Gill S, Sweet W (2013) Estimating vertical land motion from long-term tide gauge records: National Oceanic and Atmospheric Administration Technical Report NOS CO-OPS 065, p 30

Zinnert J, Brantley S, Young D (2016a) Bistability and the future of barrier islands. Nat Clim Chang 6:5-6

Zinnert J, Shiflett S, Via S, Bissett S, Dows B, Manley P, Young D (2016b) Spatial-temporal dynamics in barrier island upland vegetation: the overlooked coastal landscape. Ecosystems 19:685-697

Zinnert J, Stallins J, Brantley S, Young D (2017) Crossing scales: complexity of barrier island processes for predicting future change. Bioscience 67:39-52

Publisher's Note Springer Nature remains neutral with regard to jurisdictional claims in published maps and institutional affiliations. 